\title{
Performance Evaluation of Three PID Controller Tuning Algorithm on a Process Plant
}

\author{
Oladimeji Ibrahim*, Sulyman A. Y. Amuda**, Olatunji O. Mohammed*, Ganiyu A. Kareem*** \\ *Department of Electrical and Electronics Engineering, University of Ilorin, Ilorin Nigeria \\ **Department of Computer Engineering, University of Ilorin, Ilorin Nigeria \\ ***National Agency for Science and Engineering Infrastructure, Abuja Nigeria
}

\section{Article Info \\ Article history: \\ Received Apr 29, 2015 \\ Revised Jun 28, 2015 \\ Accepted Jul 12, 2015 \\ Keyword: \\ Control algorithm \\ PID controller \\ Plant model \\ Time response \\ Tuning parameter}

\begin{abstract}
Accurate tuning of controller in industrial process operation is prerequisite to system smooth operation which directly reduce process variability, improved efficiency, reduced energy costs, and increased production rates. Performance evaluation of a model based PID controller tuning algorithm on a chemical process plant is presented in this paper. The control action of three different PID controller tuning algorithms namely; Hagglund-Astrom, Cohen and Coon, and Ziegler-Nichols on the process plant was examined in a closed loop control configuration under normal operating condition and in the face of disturbance. LabVIEW software was used to model a chemical process plant from open loop control test data. The time domain response analysis of the controllers shows that each tuning algorithm exhibit different time response. Ziegler-Nichols algorithm shows the best performance with fastest rise time, settling time and was able to restore the system back to normal operating condition in a short time when subjected to disturbance compare to Cohen \& Coon controller and Hagglund-Astrom algorithm settings.
\end{abstract}

Copyright (C) 2015 Institute of Advanced Engineering and Science. All rights reserved.

\section{Corresponding Author:}

Oladimeji Ibrahim

Department of Electrical and Electronics Engineering,

University of Ilorin,

PMB 1515, IlorinNigeria.

Email: reacholaibrahim@gmail.com

\section{INTRODUCTION}

Control system regulates flow of energy or matter and its importance cannot be over emphasised in all facets of human activities from domestic operations to industrial applications. Industrial process plant comprises of series of process units interconnected and the ability to continuously measure and control the process variables (PV) is prerequisite to smooth running and optimization of the system. The most commonly used control system in industrial application is the proportional integral and derivative controller (PID) due to its simplicity and robustness [1-4]. Accurate tuning of the control system is necessary for system best performance which directly reduce process variability, maximize system efficiency, minimize energy costs, and increased production rates. The tuning of a controller involves setting the targeted performance by specifying desired output that can be maintain throughout the process operation irrespective of process variability and surrounding condition.

A PID Controller is a feedback automatic control system that integrates proportional (P), integral (I) and derivative (D) modes which can be arranged in series, ideal or parallel structures [5]. PID controller operates by summing the control action of the proportional, the integral and derivative action to produce a common control signal that is applied to the system under control [6, 7]. The proportional control mode changes the controller output in proportion to the error $(e)$ and the adjustable setting is called the proportional 
gain $k_{p}$ sometimes referred to as proportional setting. The time and Laplace domain representations of proportional controller is given by equation (1) and (2).

Time domain, $u_{c}(t)=k_{p} e(t)$

Laplace domain, $U_{c}(s)=k_{p} e(s)$

Where, $u_{c}(t)$ and $e(t)$ are the control and error signals

The integral control mode of a PID controller produces a long term corrective change in controller output by driving the error offset to zero. It appears as a ramp of which the slope is determined by the size of the error and the adjustable setting is termed integral time $T_{i}$ called the I-setting of the controller. The time and Laplace domain representations for integral controller is presented by equation (3) and (4).

$$
\begin{aligned}
& \text { Time domain: } u_{c}(t)=K_{I} \int_{0}^{t} e(t) d t=K_{p} \frac{1}{T_{i}} \int_{0}^{t} e(t) d t \\
& \text { Laplace domain: } U_{c}(s)=\left[\frac{k_{I}}{s}\right] e(s)
\end{aligned}
$$

The derivative control is rarely used in controller application as it is very sensitive to measurement noise and can make tuning very difficult but it has advantage of making control loop respond faster with less overshoot. Its adjustable setting is called derivative time $T_{d}$. The time and Laplace domain representations are given by equation (5) and (6).

Time domain $u_{c}(t)=k_{D} \frac{d e(t)}{d t}=k_{p} T_{d} \frac{d e(t)}{d t}$

Laplace domain: $U_{c}(s)=\left[k_{D} s\right] e(s)$

The effective control signal provided by the PID controller is summation of the three control terms represented in time and Laplace domain as $[1,6,8]$.

$$
\begin{aligned}
& u(t)=k_{p} e(t)+K_{I} \int_{0}^{t} e(t) d t+k_{D} \frac{d e(t)}{d t} \\
& U(s)=\left[k_{p}+\frac{k_{I}}{s}+k_{D} s\right] e(s)
\end{aligned}
$$

The best controller settings is expected to give fastest response in terms of system rise time, minimum settling time, least overshoot, and zero steady state error. The classical controller design employs system model for studying controller performance under different operating condition before real time implementation. A system model is obtained from existing model, developed from new mathematical relation or using modelling software taken in to consideration all the observable variables of the system [8]. The methods for tuning PID controller are broadly classified to open loop and closed loop technique. In open loop method, the controller parameters are obtained manually from open loop test data of the plant under consideration. In closed loop method, the controller parameters is automatically tuned when the plant is operated in closed loopmode. The most commonly used closed loop methods includes Ziegler-Nichols method, Tyreus-Luyben method and damped oscillation method, while open loop method are the open loop Ziegler-Nichols method, Cohen and Coon method, Fertik method and Hagglund-Astrom method [9].

In this paper, three different PID controller tuning algorithms, namely; Hagglund-Astrom, Cohen and Coon, and Ziegler-Nichols are used to design PI controller settings for a chemical process plant. The 
controller design process involves development of process plant model from laboratory open loop test data of the plant using Laboratory Virtual Instrumentation Engineering Workbench (LabVIEW) software. The PI controller gain parameters were calculated from three PID tuning controller algorithms and implemented in LabVIEW control simulator to study the performance of the obtained settings. The results shows that the transient response of the three controller differs with Ziegler-Nichols method showing the fastest transient response.

\section{PLANT MODELLING}

Theprocess plant open loop step responsetest data was used to model the plant from which plant parameters were obtained for controller settings calculations. The test data was logged in excel spread then uploaded to LabVIEW control toolbox to generate the plant response graph as shown in Figure 1. Using continuous single input single output (SISO) array block. The LabVIEW software was used to analyse the system response-to-step input $u(t)$ stimulus to estimate the plant transfer function.

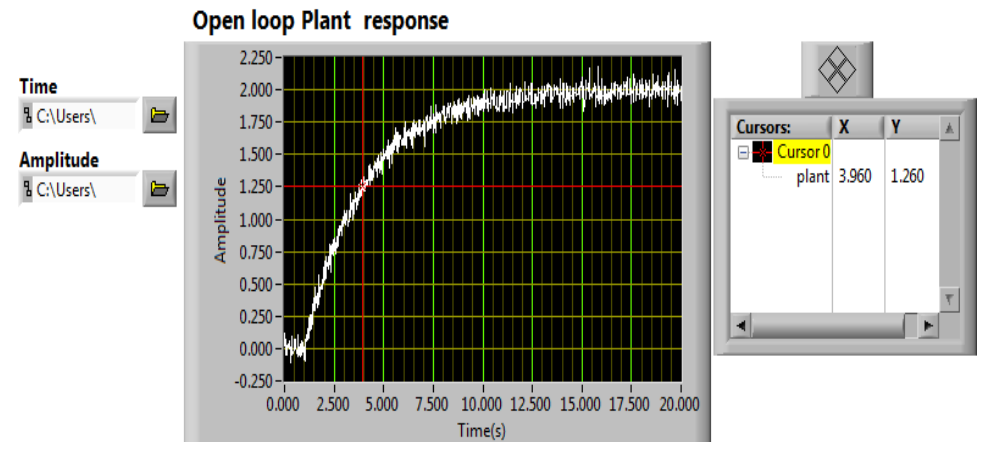

Figure 1. Plantresponse to step input

The time response in Figure1 shows that the plant is a first-order system characterized with timedelay at transient.The transfer function of first order system plus delay is given by the expression of equation (9) $[1]$.

$$
\text { Transfer Function, } G(s)=\frac{k e^{-t_{d} s}}{\tau s+1}
$$

Where, $k$ is plant gain and $\tau$ is time constant (s)

The time response to a step input of a first order system with respect to the gain amplitude isexpress as;

$$
Y(t)=1-e^{-\frac{t}{\tau}}
$$

At time $t=\tau$,the plant response amplitude $Y(t)$ is expected to have reach $63.2 \%$ of its final value [10]. At $63.2 \%$ of $Y(t)$, the plant corresponding gain amplitude is 1.26 at a time of 3.96 seconds.

The dead $\left(t_{d}\right)$ time associated to the plant response is estimated to be 1 sec as observed from the plant response graph(Figure 1), therefore the plant time constant $(\tau)$ is estimated to be(3.96 - 1) seconds.

Plant parameters: Plant gain $k$ is 2 , the time constant $\tau$ is 2.96 sec. The estimated plant model of the process plant based on (9) yields:

$$
\text { Plant transfer function, } G(s)=\frac{2 e^{-1 s}}{2.96 s+1}
$$


The obtained plant transfer function shows that the system is a first order system with time delay. The model parameters wereused in the section three (3) for controller settings calculations and simulation implementation. The exponential term $(e)$ in the plant model (11) is as a result of time delay associated with the plant response [10].

\section{CONTROLLER DESIGN AND IMPLEMETATION}

The controller tuningparameters were calculated for both the proportional and integral gain based on three tuning algorithm namely; Hagglund-Astrom tuning algorithm, Cohen and Coon tuning algorithm, and Ziegler-Nichols tuning algorithm as follows.

\subsection{Hagglund-Astrom Controller Settings}

The tuning algorithm or Hagglund-Astrom tuning settings is presented in Table 1 [7].

Table 1. Hagglund-Astrom design parameters

\begin{tabular}{ccc}
\hline Plant Transfer Function G(s) & Proportional Gain $\left(\boldsymbol{k}_{\boldsymbol{p}}\right)$ & Time Constant $\left(\boldsymbol{\tau}_{\boldsymbol{I}}\right)$ \\
\hline$\frac{K e^{-\theta s}}{s}$ & $\frac{0.35}{K \theta}$ & $7 \theta$ \\
$\frac{K e^{-\theta s}}{\tau \mathrm{S}+1}$ & $\frac{0.14}{K}+\frac{0.28 \tau}{\theta K}$ & $0.33 \theta+\frac{6.8 \theta \tau}{10 \theta+\tau}$ \\
\hline
\end{tabular}

From the plant model (11),

Plant delay $t_{d}=\theta=1$ sec, gain amplitude $k=2$, and time constant $\tau=2.96$.

Using PI terms of Table 1 , theproportional gain $k_{p}=0.484, \tau_{I}=1.883$, and $k_{I}=0.257$

Transfer function ofPI controller,

$$
U(s)=\left[\frac{k_{p} s+k_{i}}{s}\right]
$$

Therefore, the controller setting yields transferfunction of equation (13).

$$
U(s)=\left[\frac{0.484 s+0.257}{s}\right]
$$

\subsection{Cohen and Coon Controller Setting}

TheCohen and Coon controller setting for a first order system plus dead time is presented in Table 2 [11, 12].

Table 2. Cohen and Coon design parameters

\begin{tabular}{ccc}
\hline Plant Transfer Function G(s) & Proportional Gain $\left(\boldsymbol{k}_{\boldsymbol{p}}\right)$ & Integral Time Constant $\left(\boldsymbol{\tau}_{\boldsymbol{I}}\right)$ \\
\hline$\frac{K e^{-\theta s}}{s}$ & $\frac{1}{K} \frac{\tau}{\theta}\left[0.9+\frac{\theta}{12 \tau}\right]$ & $\frac{\theta\left[30+3\left(\frac{\theta}{\tau}\right)\right]}{9+20\left(\frac{\theta}{\tau}\right)}$ \\
\hline
\end{tabular}

The proportional and integral gain parameters were obtained based on the Table 2 algorithm:

$k_{p}=1.373, \tau_{I}=1.968$, and $k_{I}=0.697$

The transfer function for the Cohen and CoonPI controller settings is presented in equation (14)

$$
U(s)=\left[\frac{1.373 s+0.697}{s}\right]
$$




\subsection{Ziegler-Nichols Controller Settings}

The Ziegler-Nichols method was based on process reaction curve method with the assumption that process control has open loop step response like -S-shape as shown in Figure 2. The PID controller parameter settings were obtained using the Ziegler-Nichols algorithm presented in Table $3[8,13]$.

Table 3. Ziegler-Nichols step response tuning parameters

\begin{tabular}{cccc}
\hline Controller Structure & Proportional Gain $\left(K_{P}\right)$ & Integral Time Constant $\left(\tau_{I}\right)$ & Derivative Time Constant $\left(\tau_{\boldsymbol{D}}\right)$ \\
\hline Case (i) $\mathrm{P}$ & $\frac{1}{R_{N} L}$ & & \\
Case (ii) PI & $\frac{0.9}{R_{N} L}$ & $3 L$ & \\
Case (iii) PID & $\frac{1.2}{R_{N} L}$ & $2 L$ & $0.5 L$ \\
& & & \\
\hline
\end{tabular}

$R_{N}=\frac{\Delta y / \Delta T}{\Delta u}, \Delta y / \Delta T$ is the slope of point of point of inflexion of the process reaction curve and $\Delta u$ is the height of the reaction curve.

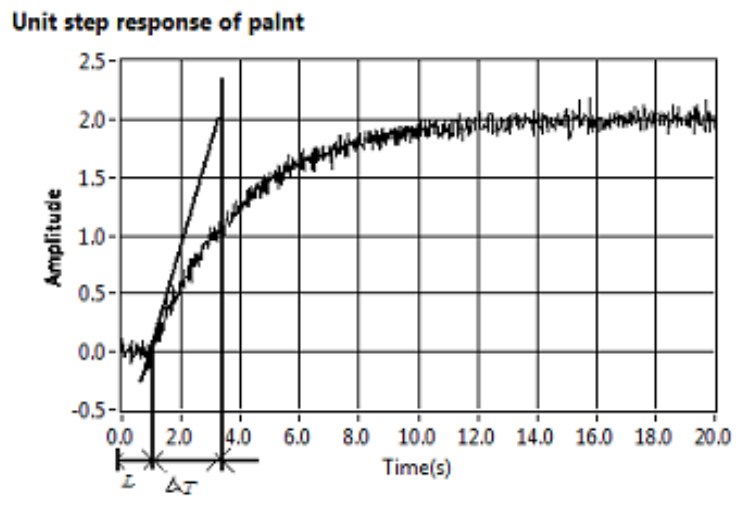

Figure 2. Plantresponse

From the response curve in Figure 2

$$
\begin{aligned}
& \frac{\Delta y}{\Delta T}=\frac{2-0}{3.5-1}=0.8, \text { and } \Delta u=k=2, \\
& R_{N}=\frac{0.8}{2}=0.4
\end{aligned}
$$

Considering case (ii) which is PI term of the Ziegler-Nichols tuning algorithm, the controller parameters was estimated as follows:

The proportional gain $k_{p}=2.25, \tau_{I}=3$, and $k_{I}=0.75$

$$
\text { The controller transfer function } U(s)=\frac{2.25 s+0.75}{s}
$$

The performance of the obtained settings for the threePI controller settingson the process plant under normal operating condition and with disturbances was investigated. The closed loop systemwas simulated in LabVIEWsoftware with a step change in the set-point followed by a unit step disturbance after 40 seconds as presented inthe simulation block of Figure 3. 


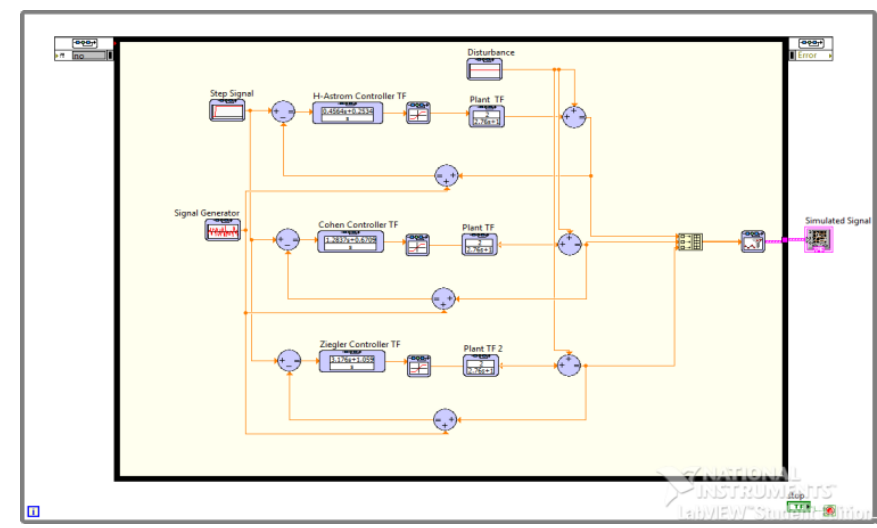

Figure 3. PI controller closed loop simulation

\section{RESULTS AND ANALYSIS}

The time response parameters for Hagglund-Astrom, Cohen and Coon, and Ziegler-Nichols controllers tuning setting on the chemical process plant under closed loop operation is presented in Table 4. It shows each controller time response performance on the plant with respect to the desirable specifications of rise time, settling time, percentages overshoot, and peak value.

Table 4. Time response parametric data

\begin{tabular}{cccccc}
\hline Controllers & Rise Time (s) & Overshoot (\%) & Steady State Gain & Settling Time(s) & Peak Value \\
\hline Hagglund-Astrom & 4.210 & 3.115 & 1 & 16.237 & 1.031 \\
Cohen \&Coon & 1.896 & 3.902 & 1 & 10.426 & 1.039 \\
Ziegler-Nichols & 1.172 & 0 & 1 & 4.689 & 0.999 \\
\hline
\end{tabular}

The Ziegler-Nichols controller has a fastest rise time of $1.172 \mathrm{sec}$, settling time of 4.689 and with no overshoot. The Cohen and Coon controller exhibit a moderately slow response, the rise time is 1.896 sec with settling time of $10.426 \mathrm{sec}$ and $3.902 \%$ overshoot. The Hagglund-Astrom controller settings responded with longest time delay of $4.210 \mathrm{sec}$, settling time of $16.237 \mathrm{sec}$ but it has lesser overshoot of $3.115 \%$ compare to the Cohen and Coon response. The response parametric data shows that the Ziegler-Nichols tuning method is much better for designing controller for a first order system plus dead time compared to others other two tuning methods haven demonstrated fastest process response time, shortest settling time with no overshot.

In order to further investigate the robustness of each controller setting, the closed loop system was subjected to disturbance at interval to reveal each controller disturbance rejection capability. The system response presented in Figure 4 showing the behaviour of the plant under normal operating condition and when subjected to disturbance at 40 seconds.

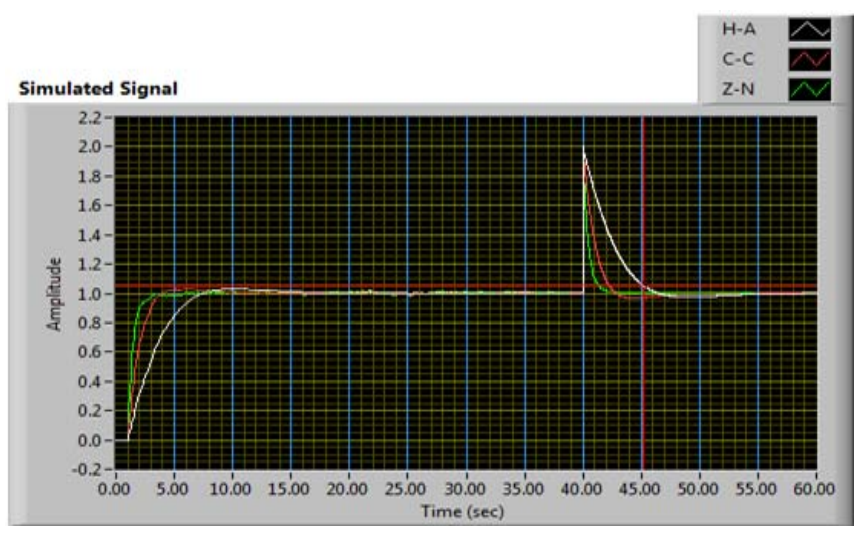

Figure 4. Controller response to disturbance 
The Ziegler-Nichols controller demonstrated strongest ability to restore the system back to normal operation in the face of disturbance at shortest time of 2 sec. It took about $3 \mathrm{sec}$ for the Cohen and Coon controller to restore the plant and Hagglund-Astrom controller could only bring the system to normal operating condition after $5 \mathrm{sec}$, as shown Figure 4. A controller tuning objective is to feed settings parameters that will provide the best control action for smooth process operation under normal operating condition and when there is disturbance. The ability of Ziegler-Nichols controller to reject the disturbance in earliest time and the fast transient response demonstrated shows its better method for tuning process plant plus delay as compared to Cohen and Coon and Hagglund-Astrom method.

\section{CONCLUSION}

A process plant has been modelled from open loop test data, and three various PID controller algorithm were used to designed controller parameter for the system. The plant transfer function reveals that the system is a first order plus delays.Three differentcontroller tuning algorithm were used to calculate PI controller settings and implemented in LabVIEW control-tool kit. The system continuous time domain response shows thestability and robustness ofeach controlleron the plant under normal operating condition and when subjected todisturbances. The time domain response shows that Ziegler-Nichols controller exhibits the best performance with fastest rise time, settling time and ability to restore the system back to normal operating condition in earliest time in the face of disturbance. The Cohen\& Coon controller performance was moderately better as compare to Hagglund-Astromsettings.

\section{REFERENCES}

[1] K.J. Åström and T. Hägglund, Advanced PID control: ISA-The Instrumentation, Systems, and Automation Society; Research Triangle Park, NC 27709, 2006.

[2] J. Basilio and S. Matos, "Design of PI and PID controllers with transient performance specification", Education, IEEE Transactions on, vol. 45, pp. 364-370, 2002.

[3] S.N.S. Salim, M. Rahmat, A. Faudzi, Z. Ismail, N. Sunar, and S.A. Samsudin, "Robust Control Strategy for Pneumatic Drive System via Enhanced Nonlinear PID Controller", International Journal of Electrical and Computer Engineering (IJECE), vol. 4, pp. 658-667, 2014.

[4] M.R.R. Khoygani, S. Hajighasemi, and D. Sanaei, "Designing and Simulation for Vertical Moving Control of UAV System using PID, LQR and Fuzzy logic", International Journal of Electrical and Computer Engineering (IJECE), vol. 3, pp. 651-659, 2013.

[5] K.H. Ang, G. Chong, and Y. Li, "PID control system analysis, design, and technology", Control Systems Technology, IEEE Transactions on, vol. 13, pp. 559-576, 2005

[6] J. Smuts, "PID Controllers Explained", Canadian Process Equipment \& Control News, vol. 2, 2002.

[7] K.J. Aström and T. Hägglund, "PID controllers: theory, design and tuning", 1995.

[8] R. Burns, Advanced control engineering: Butterworth-Heinemann, 2001.

[9] P. Cominos and N. Munro, "PID controllers: recent tuning methods and design to specification", IEE ProceedingsControl Theory and Applications, vol. 149, pp. 46-53, 2002.

[10] K.S. Patil and D. Patil, "Effective Teaching Learning Process for PID Controller Based on Experimental Setup with LabVIEW".

[11] G. Cohen and G. Coon, "Theoretical consideration of retarded control", Trans. Asme, vol. 75, pp. 827-834, 1953.

[12] J.F. Smuts, "Process control for practitioners", League City, TX: OptiControls Inc, 2011.

[13] J.G. Ziegler and N.B. Nichols, "Optimum settings for automatic controllers", trans. ASME, vol. 64, 1942.

\section{BIOGRAPHIES OF AUTHORS}

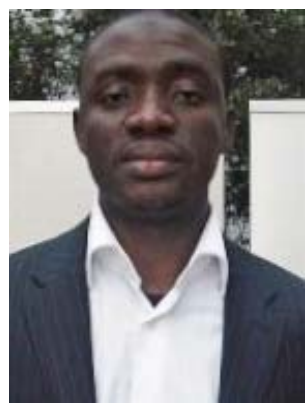

Oladimeji Ibrahim received the B.Eng degree in Electrical Engineering from University of Ilorin, Nigeria in 2005, Masters degree in Instrumentation and Control from Glasgow Caledonian University, UK in 2009, and currently pursuing a Ph.D. at Electrical and Electronics Engineering Department, Universiti Teknologi PETRONAS (UTP), Malaysia. His research interests include digital control of power electronics, switching power converters, and renewable energy. He is a member of The Institute of Measurement and Control (MInstMC, UK), ), member of The Nigerian Society of Engineers (MNSE) and student member of the IEEE. 


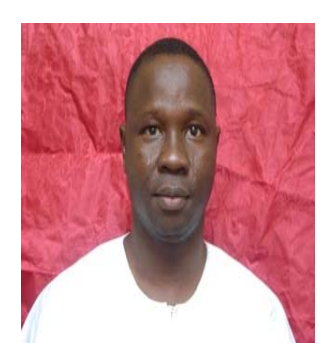

Sulyman A.Y. Amuda is a Ph.D. holder in Electrical Engineering from University of Ilorin, Nigeria, where he also earned his M.Eng degree. His research interest is in speech processing, renewable energy conversion, computer simulation and control. He is a Fulbright Scholar, researcher, and presently lectures in the Computer Engineering Department, University of Ilorin, Nigeria. He was a visiting researcher at the Center for Robust Speech System, University of Texas, Dallas, in 2009-2010 for nine months. He is a registered professional engineer in Nigeria (COREN), member of the Nigerian Society of Engineers (NSE), and IEEE Member.

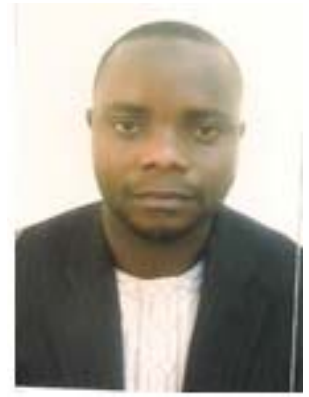

Olatunji Obalowu Mohammed received B.Eng degree in Electrical and Electronics Engineering from Bayero University, Nigeria in 2010, Masters degree in Electrical and Electronics from Coventry University, UK in 2014. His research interests include power system control and renewable energy integration and control. He is a member of the Institute of Electrical and Electronics Engineers (MIEEE) and member of Nigerian Society of Engineers (MNSE). He is curently a lecturer in the department of Electrical and Electronics Engineering, University of Ilorin, Nigeria.

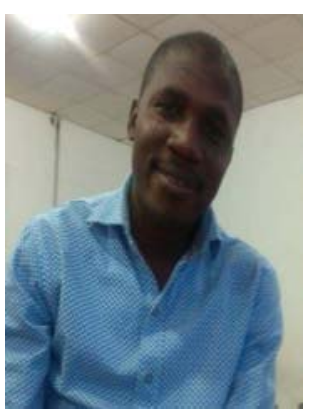

Kareem Aduagba Ganiyu received the B.Eng degree in Mechanical Engineering from University of Ilorin, Nigeria in 2004, and currently pursuing a Master's degree at Mechanical Engineering Department, Federal University of Technology, Minna Nigeria. His research interests include corrosion and green inhibitors, Material selection and applications and renewable materials and energy sources. He is a member of Nigerian Society of Engineers (MNSE), a member, Nigerian Institution of Mechanical Engineers (MNImechE) and a member of the council for the Regulation of Engineering in Nigeria (COREN) 